This is an Accepted Manuscript version of a chapter accepted for publication in Appelqvist $\mathrm{H}$ (ed.) Wittgenstein and the Limits of Language. Routledge Studies in Twentieth-Century Philosophy. London: Routledge, pp. 46-64. https:// www.routledge.com/Wittgenstein-and-the-Limits-of-Language/Appelqvist/p/book/978081538501. It is deposited under the terms of the Creative Commons Attribution-NonCommercial License (http://creativecommons.org/licenses/by$\mathrm{nc} / 4.0 /$ ), which permits non-commercial re-use, distribution, and reproduction in any medium, provided the original work is properly cited.

\title{
SOLIPSISM AND THE GRASPABILITY OF FACT
}

\begin{abstract}
Wittgenstein's Tractarian discussion of solipsism opens with the claim that '[ $t]$ he limits of my language mean the limits of the world' (TLP 5.6.) According to this paper, Wittgenstein expresses here a thought that the subject makes no sense of her thinking having content going beyond in kind that which she possesses in thinking. What the subject possesses in thinking is furthermore a truth or falsity, so that the idea is ruled out of truth-independent substance to the world. At the same time, however, thinking is an act of the subject given to her only as such - only as something she does, and so only as a determination of herself. Truth is not therefore independent of the subject; rather, as Wittgenstein puts it, 'the world is my world' (TLP 5.62). This conclusion threatens an idealism under which the nature of truth is explained by reference to that of the subject; objectivity is grounded in a deeper subjectivity. This threat is deflected by the recognition that the solipsist's subject is an essentially undistanceable 'I' without content or character, so that 'solipsism strictly carried out coincides with pure realism' (TLP 5.64).
\end{abstract}

\section{INTRODUCTION}

At the start of his Tractarian discussion of solipsism, Wittgenstein sets out in two sections how the solipsist is in a certain manner correct:

5.6 The limits of my language mean the limits of my world.

5.62 This remark provides the key to the question, in what way solipsism is a truth.

In fact what solipsism means, is quite correct, only it cannot be said, but it shows itself.

The world is my world: this shows itself in the fact that the limits of the language (the language which alone I understand) mean the limits of my world. ${ }^{1}$

Between these two is section 5.61 which stands apart from its immediate neighbours by making no use of the first person singular, and with that by bearing no obvious connection to solipsism:

5.61 Logic fills the world: the limits of the world are also its limits.

We cannot therefore say in logic, 'The world has this in it, and this, but not that'.

For that would apparently presuppose that we exclude certain possibilities, and this cannot be the case since it would require logic to go beyond the limits of the world: that is, if it could consider these limits from the other side also.

What we cannot think, that we cannot think: we cannot therefore say what we cannot think.

The history of the passage's composition marks 5.61 as an intruder. The ancestors of 5.6 and 5.62 in the Notebooks have nothing intervening correlating to 5.61. And the solipsism passage of Prototractatus is a sentence by sentence match with that of the Tractatus, apart

\footnotetext{
${ }^{1}$ I shall throughout be using the Ogden translation of the Tractatus.
} 
from the absence of any correlate to 5.61 whose content appears later on. (The words 'This remark' at the start of 5.62 unquestionably refer not to 5.61 but to 5.6.) At some late stage of the book's composition, Wittgenstein decided that the apparently impersonal comments of 5.61 , comments which had initially been placed elsewhere, should be relocated to join the first personal discussion of 5.6 and 5.62 .

In this essay, I shall seek to understand Wittgenstein's treatment of solipsism by considering first section 5.61. Subsequently I shall turn to sections 5.6 and 5.62 . Finally, in the third part of the essay, I shall consider central themes of the $5.63 \mathrm{~s}$ and $5.64 \mathrm{~s}$. It's not obvious up front that this strategy will be fruitful. Just because 5.61 was originally separated from 5.6 and 5.62 doesn't mean an understanding of it will be available independently of these sections. Similarly, the fact that 5.6 and 5.62 precede the $5.63 \mathrm{~s}$ and $5.64 \mathrm{~s}$ provides no guarantee that an interpretation can be successful which examines them in that order. But still, let's see what we can do.

\section{PART 1: TLP 5.61}

\section{1}

The limits of logic are the limits of the world. What does this mean?

The Tractarian world is the totality of facts (TLP 1, 1.1), and so it might be thought momentarily that by the limits of the world, Wittgenstein will mean the boundary between the facts and the non-facts, the boundary between the actual and the non-actual. Evidently, though, this is not Wittgenstein's intention. There is no concern in 5.61, or indeed anywhere in the 5.6s, with a contingent divide between what is so and what is not. The effect of Wittgenstein's talk of limits, rather, is to signal a concern with something non-contingent, namely the space comprising indifferently both what is so and what is not. It signals a concern, that is to say, with the space of the possible. Talk of limits has a similar effect in application also to logic or language. Here again consideration is moved away from any contingent, empirical totality of propositions - the propositions of English, say, or of Japanese - and moved on to the non-contingent matter simply of what may be said. Wittgenstein is concerned, that is to say, not with any empirically circumscribed set of propositions, but with the non-contingent space of the sayable, the space of sense. Wittgenstein's identification of the limits of logic and the limits of the world is thus a reexpression of the Tractarian theme, familiar from elsewhere, that 'what is thinkable is also possible' (TLP 3.02) and vice versa.

But what is the theme? What does the identification mean? Let's begin towards an answer to this question by considering something Wittgenstein doesn't intend by the identification, namely a proposal that sense and possibility are identical in extent. And for this, it will be useful to talk in terms of 'object-combinations'. A possibility for Wittgenstein is a possible way for things to be, where in the basic, atomic case this is a possible objectcombination, a possibility that certain objects stand together in a certain manner. Similarly, a sense is a thinkable way for things to be, a way things can be thought to be, where in the elementary case this is a thinkable object-combination. A thinkable object-combination, Wittgenstein thus holds, is also a possible object-combination. So expressed, however, the position is liable to be misunderstood. Specifically, it is liable to be miscast as a thesis that representability and possibility co-extend within a more general space of objectcombination, a thesis held against an alternative that sense is wider in extent within that space than possibility.

A disagreement as to whether thinkability extends beyond possibility could take the form either of a disagreement about the extent of thinkability, or of a disagreement about 
the extent of possibility. If Wittgenstein were to hold a thesis that what is thinkable is also possible, his opponent could be someone who overestimates sense, maintaining that certain impossible object-combinations are thinkable. Or his opponent could be someone who underestimates possibility, maintaining that certain thinkable combinations are impossible. Either way, we may however note, Wittgenstein's entering into a disagreement with the opponent will mean his allowing the specification of an object-combination which is not as such the specification of a possibility. In the second case, Wittgenstein allows sense to his opponent's view that certain specifiable object-combinations are impossible. And in the first, Wittgenstein himself specifies impossible object-combinations, maintaining against his opponent that such things cannot be thought. It is evident from what Wittgenstein goes on to say in 5.61, however, that the specification of an impossible object combination is not to be countenanced:

We cannot therefore say in logic, 'The world has this in it, and this, but not that'.

For that would apparently presuppose that we exclude certain possibilities, and this cannot be the case since it would require logic to go beyond the limits of the world. (5.61)

There is no saying that this combination is a possibility, and this, but not that. For that would mean excluding certain combinations from possibility, or certain would-be possibilities from being genuine. And for this we would need logic to go beyond the limits of the world.

Not only, then, does Wittgenstein reject the idea of specifying an objectcombination whilst leaving it open whether that combination is possible, he further explains that rejection as a consequence of the identity of limits between logic and the world. Transparently, we need a different understanding of that identity, one which does not construe it as a thesis about the relative extents of representability and possibility within a space of object-combinations.

\section{2}

Let's look back to Wittgenstein's opening remarks in his book on the combining of objects. Wittgenstein introduces his notion of an object with the statement:

2.01 An atomic fact is a combination of objects (entities, things).

He continues:

2.011 It is essential to things that they should be possible constituents of atomic facts.

And indeed:

2.014 Objects contain the possibility of all states of affairs.

The range of possible facts, the space of possibility, is implicit within the essential nature of the Tractarian objects. This idea that combinatorial potential is contained within the nature of the objects bears, however, two rather different understandings. It can be understood as the stance that an object's possibilities for combining in facts are a product of its essential nature. The object's combinatorial possibilities are grounded in its essential nature, much as the essential natures of certain geometrical shapes ground their possibilities together for tessellation. Or it can be understood as a view that the object's essential nature consists in its combinatorial possibilities, that the combinatorial powers are written into the object at the 
start as constitutive of its essential nature. In his ensuing comments, Wittgenstein repeatedly rejects the former view and asserts the latter:

2.012 In logic nothing is accidental: if a thing can occur in an atomic fact, the possibility of the atomic fact must be prejudged in the thing.

$2.0121 \mathrm{It}$ would, so to speak, appear as an accident, when to a thing that could exist alone on its own account, subsequently a state of affairs could be made to fit.

If things can occur in atomic facts, this possibility must already lie in them....

Just as we cannot think of spatial objects at all apart from space, or temporal objects apart from time, so we cannot think of any object apart from the possibility of its connexion with other things.

...

2.0123 If I know an object, then I also know all the possibilities of its occurrence in atomic facts.

(Every such possibility must lie in the nature of the object.)

A new possibility cannot subsequently be found.

There is no having an object in view and then subsequently considering what possibilities it has for combination, no 'finding out' as a 'kind of accident' that this is a way the object can combine. Rather, what an object essentially is, Wittgenstein insists, is a possible part of facts.

It is a straightforward consequence of this conception of objects that the idea of an impossible object-combination, a combination which 'goes against the natures of the entities there combining' is incoherent. Nothing is specified by 'these objects, in this way, where this is not a way these can combine'. On Wittgenstein's conception of an object, to speak of certain objects combining is to speak of a certain joint potential being actual. And it is immediately incoherent, immediate nonsense, to talk of potential being actual in a manner which is not an actualization of that potential. (Consider by comparison the idea of a 'chess move in which a castle goes diagonally'. Whilst pieces of wood can of course be physically relocated anywhere on a board, a chess piece is understood only by reference to its potential for chess movement, so that the idea is straightforwardly incoherent of a chess castle moving diagonally.) The stance expressed in 5.61 that we cannot say in logic that the world has this in it but not that, and explained there as issuing from the identity of limits between logic and the world, is thus a consequence of what appears earlier in the book as a certain priority of facts over objects. It is dictated by that priority that an object-combination is as such a possibility.

\section{3}

So there must be a close link between Wittgenstein's conception of fact and object and the identity of limits between logic and the world. With this in mind, let's ask after the source of the conception. Where does the idea come from of objects as essentially and exhaustively possible parts of facts? Why should that be a basic structuring of reality? Here I'm going to present what for now will appear a dogmatic account. There will be considerably more discussion as the essay progresses.

Frege writes:

What is distinctive about my conception of logic is that I begin by giving pride of place to the content of the word 'true', and then immediately go on to introduce a thought as that to which the question 'Is it true?' is in principle applicable. So I do not begin with concepts and put them together to form a thought or judgement; I come by the parts of a thought by analyzing the thought. (Frege 1979: 253) 
This distinctive Fregean conception of logic is also, I suggest, that of the Tractatus. Like Frege, Wittgenstein gives pride of place to truth, and introduces a fact, or way for things to be, or an object-combination, as that to which the question 'Is it true?' has application. A fact is something which may obtain or not, and such obtaining is the matter precisely of truth. (Here and below I will typically use the word 'fact' non-factively to cover also possibilities which do not obtain. This use should not I hope give rise to confusion; it is present also in the Tractatus (see e.g. 2.1).)

It is uncontroversial of course that Tractarian facts are the kinds of things to obtain, and that such obtaining is in some manner the matter of truth. But paralleling Frege means taking a more specific line. For one, Frege is not merely using the notion of truth to single out certain items - thoughts - in which he is interested. Rather, he is introducing the notion of a thought as the notion of something which may be true: a thought is precisely a possible truth. 'The most appropriate name for a true thought,' Frege says, 'is a truth' (Frege 1979: 168). Similarly, I want to suggest, a Tractarian fact is not singled out merely as something whose obtaining makes for truth, something which as it happens plays a 'truth-making role', as do the facts of Russell's 1910 correspondence theory. Rather, a fact is precisely a possible truth. The most appropriate name for an obtaining Tractarian fact is a truth.

More than this though, there is also the inference of Frege's second sentence. It follows from the pride of place he assigns to truth, Frege writes, that he does not begin with the parts of a thought and put them together to form the whole but comes by the parts of the thought only by analyzing the whole. How so?

We can imagine a view of thoughts, or facts, under which these are essentially the kinds of things to be true, essentially things for which the question of truth arises, but which nonetheless have parts arrived at independently of the whole. According to such a view, whilst the parts are in themselves quite separate from any matter of truth, the manner of their combination makes truth internal to the whole: the 'self-standing' parts are combined in an essentially true-or-false manner to make an essentially true-or-false whole. Frege implies, however, that such a view would be contrary to his conception of logic. Why? Well, because the view proposes substance to the whole, the thought or fact, independent of the notion of truth. It is evident in Frege's drawing the inference he does, from truth's pride of place to parts arrived at only by analyzing the whole, that on his conception of logic truth has sole pride of place, where this means that no substance arrives into his theorising separately from that content. His theorising is in this sense nothing other than an unpacking of the notion of truth. So in particular no elaboration of his notion of a thought can be in view other than its unpacking as the notion of a truth or falsehood. And this means that the parts of a thought have no understanding other than as such. What a thought part is, exhaustively and from the start, is a part of thoughts.

It is for this same reason, I want to suggest, that Wittgenstein adopts his parallel conception of objects as essentially possible parts of facts. It is because he gives sole pride of place to the notion of truth, and so conceives of facts as nothing other than possible truths, that Wittgenstein comes by the parts of a fact only by analyzing the fact. It is for this reason that objects have no substance other than as fact elements.

\section{4}

Where are we? We rejected that the identity of limits between logic and the world is a thesis that representability and possibility are identical in extent, for such a thesis would depend for its intelligibility upon something Wittgenstein sees as ruled out by the identity, namely the specification of an object-combination which is not as such the specification of a possibility. Looking for an alternative understanding of the identity, we noted that an objectcombination's being as such a possibility issues from a certain conception of fact and object, a conception which is in turn, I suggested, the result of the pride of place Wittgenstein 
ascribes in his theorising to truth. To understand the identity of limits, this implies, we need to understand its connection to truth's pride of place. And what is necessary for this, I want now to say, is to put together our two uses of the word 'logic'. As initially introduced in connection to 5.61 , logic had to do with sense, to do with representability or sayability. In context with Frege, logic had to do with truth. Seeing these as two sides of the same coin will complete our understanding for now of 5.61. An obtaining possibility is nothing other than a truth: this explains the identity of limits between possibility and representability, for a truth or falsehood is as such a sense, and vice versa.

A Fregean thought is essentially something to be thought, or more specifically it is essentially something to be grasped. But this does not mean, of course, that empirical subjects with their contingent powers and constraints are thereby internal to the nature of thoughts. That would be psychologism of a kind Frege rejects time and again. Rather, the thought's essential graspability reflects only its status as a truth or falsehood. Indeed, it is the very same status. Being a truth or falsehood means being something for the understanding, and vice versa. A truth or falsehood is as such something to be understood, and what is understood is as such a truth or falsehood. More, in being exhaustively a truth or falsehood, in having no substance independent of truth, the thought is exhaustively something for the understanding, something wholly given to the understanding, something of which understanding is possession (more on this below). And the same connection between truth and thinkability is present also in Wittgenstein. Talk of representability or thinkability does not call for Wittgenstein for consideration of representing subjects, with their psychological powers and empirical constraints. He has no more interest than Frege in such matters. Rather, the thinkability or representability in which he is interested is precisely that of a truth or falsehood.

To ascribe pride of place to truth, then, is to ascribe pride of place to the understanding, and so to representation. A fact, or way for things to be, is precisely something to be grasped. And in ascribing sole pride of place to truth, in allowing no substance from outside the understanding to figure within the understanding, no space is admitted for a division amongst ways for things to be between the possible and the impossible. That logic - truth, representability - doesn't merely belong to the world but fills the world means that possibility and thinkability, fact and sense, are one and the same. (As Wittgenstein puts it, 'One can say, instead of, This proposition has such and such a sense, This proposition represents such and such a state of affairs' (4.031).) It means that 'metaphysical form' - that is, an object's essential possibilities for combining with other objects in atomic facts - is logical form. It means, that is to say, that the world's limits are at once those of logic.

\section{PART 2: TLP 5.6 and 5.62}

\section{1}

This account of section 5.61 is importantly incomplete, for no significant understanding has been provided of Wittgenstein's conception of obtaining facts as truths. So far, the interpretation remains brute at this central point. Explanations of truth's pride of place will be considered in the work ahead, but let's turn now to sections 5.6 and 5.62. As Wittgenstein presents this pair, 5.6 states the key to the question in what way solipsism is a truth, and 5.62 turns that key.

To begin, let's consider and set aside a suggestion that 5.6 is to be explained as a consequence of 5.61. The limits of language mean the limits of the world: this expresses, we have said, a theoretical stance within which no distinction is available between the possible and the sensical. Turning then to 5.6 - 'The limits of my language mean the limits of my 
world' - this might be read as expressing a thought that no distinction is available for me, for the subject, between the possible and the sensical. And if that's right, an explanatory move may seem available from 5.61 to 5.6. The subject makes no distinction between the sensical and the possible. Why not? Well, because there is no such distinction to be made.

But there is a difficulty here of a kind which will recur below. Spelling out the mooted explanation, we shall have the following: There is no distinction to be made between the thinkable and the possible; so no one can make any such distinction; so in particular I can make no such distinction. This conclusion must surely fail as in interpretation of 5.6, however, for its ' $\mathrm{l}$ ' is the instantiation of a variable 'someone', and as such serves to pick out one of an array, or potential array, of subjects. ('No one $\varphi s^{\prime}=$ 'It is not the case that someone $\varphi s^{\prime}$.) The subject has on this interpretation become a subject, one subject amongst (potential) others. But this can't be right, for then no move will be available to 5.62. If 5.6 is to be the basis for the solipsist's claim in 5.62 that the world is my world, its first person pronouns must match the pronoun of that claim. And whatever we make of 'The world is my world', this patently does not express a thought that the world belongs to a subject, to one subject amongst possible others. (The world is Ludwig's world - lucky Ludwig!)

This reasoning may suggest that 5.6 and 5.61 should be treated as quite separate. The impersonality of 5.61 rules out, one might think, that it be understood by means of the first-personal 5.6. And understanding 5.6 by means of 5.61 involves treating its ' $m y$ ' as the indexical name of a subject, and so barring any move to the claim in 5.62 that the world is my world. 5.6 and 5.61 must therefore stand as independent premises within an argument for solipsism. I shall reject this conclusion below, centrally by rejecting that the material of 5.61 is as impersonal as it might first seem. (Indeed, it is not as impersonal as might be suggested by this essay's strategy of beginning at 5.61 and only subsequently considering the first person pronoun.) But it will take us a while to arrive there. Let's continue on, rather, by noting that throwing out the idea that 5.6 is a consequence of 5.61 does not mean throwing out the initial move which made space for it, namely the proposal to read 5.6 as expressing a thought that the subject does not distinguish between the sensical and the possible. Sticking as we may with that idea, let's rather seek a different kind of explanatory context for it.

\section{2}

A division amongst senses between the possible and the merely sensical depends, we said, on the possession by a sense of truth-independent substance. Recasting this within the mind of the subject, we shall have that countenancing a division amongst senses between the possible and the merely sensical depends upon the ascription to a sense of truthindependent substance. The subject's distinguishing amongst senses between the possible and the merely sensical - 'The world has this in it, and this, but not that' - depends upon her ascribing truth-independent substance to the content of her thoughts. And this she cannot do. She makes no sense, I shall suggest, of there being substance to what she thinks going beyond in kind what is available to her within her thinking - substance, that is, beyond truth and falsehood.

This suggestion depends upon an idea of understanding as possession: in grasping that $p$, the subject is possessed of that which she grasps. Where the subject understands that $p$, she knows herself to understand that $p$, and so she knows that what she understands is that $p$. In understanding, the subject is not merely related to a certain content as Jack might be related to Jill by being taller than her. Rather, the content of the subject's understanding, and that she understands that content, is given to her, possessed by her, in her act of understanding. This point may seem straightforward enough: the subject does not need a further act beyond her understanding in order to know herself to understand what she does. Still, it might be questioned, or at least qualified. Yes, someone might say, the subject is 
indeed possessed in thinking of the true-or-false content that she thinks. So much is indeed given to her, transparent to her, merely in thinking. But there is nonetheless further substance to what the subject thinks, deeper substance which goes beyond in kind that which is given to her in her thought. What is given to the subject in thought, the truth-orfalsity, is the mere tip of the sense iceberg whose full nature encompasses the truthindependent substance of the sense's constituent objects.

The thought of 5.6 , I want to suggest, is that this supposition of a 'deeper content' is not something of which the subject can herself make sense. The subject might, perhaps, essay the idea that she is related in her thinking to objects with a life outside truth, and so a life beyond in kind what is possessed by her in her understanding. She is thinking here about this thing. But any such idea - 'I think here of this' - will itself be simply a fact whose content available to her in thinking it will be without truth-independent substance. For what she selfconsciously thinks - what she knowingly grasps - will be simply another truth or falsehood. And the thought here is quite general. There is no move for the subject by which she can 'get outside' her understanding in such a way as to recognise a 'deeper content' to what she understands, a content going beyond in kind that which she possesses in her understanding. Any such attempt at recognition will be simply another move of her understanding, and as such deliver for her only something again of the same kind.

Recognising this, the subject sees the quest for 'truth-independent substance' as misconceived. The idea of fulfilling the quest is the contradictory idea of recognising something unrecognizable, of possessing something unpossessable. 'I make no sense,' she thus concludes, 'of my objects, the things about which I think, outrunning in their substance that which is given to me within my thought.' Or again: 'The limits of my language mean the limits of my world'.

\section{3}

Care needs to be taken in understanding this line of thought. To see why, recall our concern above to avoid seeing 5.6 as an instantiation of a generalization that there is no distinction available to a subject, to subjects, between the thinkable and the possible. If 5.6 instantiates such a generalization, then its first person pronoun will serve to pick out one amongst an array (or would-be array) of subjects, and so cannot serve to express the solipsism in view in 5.62. (More, we suggested that such a reading would be inevitable if we tried to understand 5.6 as a consequence of 5.61.) Have we now avoided what we said must be avoided?

Well, not if the reasoning is to work as follows. First premise: I make no sense of what I think having substance going beyond in kind that which I grasp in thinking it. Second premise: what I grasp in thinking something is precisely a truth or falsehood. So conclusion: I make no sense of what I think having truth-independent substance. For insofar as the second premise here introduces a notion of truth not present in the first premise, the claim that what I grasp is a truth-or-falsehood will necessarily be the consequence of a generalization that what subjects in general grasp, or possess, are truth-or-falsehoods. (If the notion of truth is independent of considerations as to what I grasp and make sense of, then the fact that what I grasp is a truth will not be explicable by reference to me, but must issue instead from considerations as to what subjects in general grasp.) And this will then infect the whole passage of reasoning: if the ' $I$ ' of the second premise is the name of one of an array of subjects, then for the reasoning to run so too must be the 'I's of the first premise. And so we shall arrive at an interpretation under which Wittgenstein's thought in 5.6 is that a certain subject, Ludwig, makes no sense of what he, Ludwig, thinks having truth-independent substance.

But this is not what the reasoning was to be. More specifically, the reasoning did not call on any independent second premise as above, separate from the first. To see why not, let's consider why, in understanding that $p$, the subject knows herself to understand that $p$, 
and so knows that what she understands is that $p$. Why by contrast does the subject not know in being taller than Jack that she is taller than Jack? The immediate response here is that the subject knows in the act of understanding that she so acts, because her so acting is a determination of herself, the subject. The subject's knowledge of her understanding is selfknowledge of a kind distinct from any knowledge she might have of being taller than Jack.

The thought here of self-knowledge is not the thought, however, that because the subject's understanding that $p$ is a determination of herself, the subject has some kind of special access to it, or has a special guarantee of knowledge. That would again involve seeing the subject here as a subject: special access or guarantee mean access or guarantee not enjoyed by another. ('This subject here - the 'I' subject, the one I have special access to/guaranteed knowledge of - understands that $p^{\prime}$.) Rather, the thought is that the subject's determinations are given to her essentially as her determinations, essentially as herself, where this means that they are not given as something which might be known 'from another perspective' other than as such. As they are known, there is no possibility of 'hiving off' their first-personality to give the shape of a situation which might be known in another manner. For this to be so would be for the subject to be a subject.

And if this is right, the subject's failure to make sense of content to her thinking going beyond in kind that which she possesses in thinking it will be a failure to make sense of content to her thinking which goes beyond herself. What the subject possesses is essentially a self-determination: this is the basic kind of that which I possess. So where I make no sense of the content of my thinking having a nature which goes beyond in kind that which I possess in thinking it, I make no sense of what I think being something separable from myself. My thinking, and with that what I think, is essentially a determination of myself. And this means that there are no distinct first and second premises as above. The thought is not that what I grasp is essentially a graspable, i.e. a truth: but what's that? Rather, it is that what I grasp is essentially something graspable by me. I make no sense of what I think having a deeper content different in kind from that which I possess, but no external or impersonal characterization is now to be given of that which I possess: a truth, a possibility, whatever. Rather, it is fundamentally as something I possess, as something I grasp, that I grasp something. And what I make no sense of is content beyond here: I make no sense of content beyond possessability by me.

The reasoning of the last section is thus run entirely in an undistancable first person, in a first person which is not and cannot be the instantiation of a third-personal generalization. There is no thought present here that I make no sense of what a certain subject - the 'me subject' - thinks having content outrunning that which is given to her - that is, to me - in thinking. The thought is rather that I make no sense of what I think outrunning that which I possess. And its avowal can be made only in the first person: the limits of my language mean the limits of my world.

\section{4}

Section 5.6 provides the key to the truth in solipsism, and in 5.62 Wittgenstein presents the turning of this key as more or less effortless. We are given only this:

The world is my world: this shows itself in the fact that the limits of the language (the language which alone I understand) mean the limits of my world. (5.62)

An obvious point for the interpreter to focus on here is Wittgenstein's apparent identification of the limits of the language with the limits of the language which alone I understand. Connecting to 5.6, this is, apparently, an identification between the limits of the language and the limits of my language. Such an identification certainly promises to take us to the solipsist's conclusion. If the limits of my language mean the limits of my world (5.6) and the 
limits of the language mean the limits of the world (5.61), then if the limits of my language are the limits of the language we shall have both that the limits of the language mean the limits of my world and that the limits of the world mean the limits of my world. The world will be my world. Indeed, identifying the limits of the language and the limits of my language is surely not only sufficient but also necessary for the solipsist's conclusion. Without this, we shall have only identities with the first person pronoun on both sides, or identities with the first person pronoun on neither side (see Sullivan 1996: 195).

There is good reason, however, to reject this perspective from which the understanding and justification of a 'cross-identification' appears the crucial matter for interpretation. For as Wittgenstein presents to his reader, the 'cross-identification' of language and my language discernible in 5.62 is not the key to solipsism. Indeed, it is not even a key, an additional key to work alongside that of 5.6. Rather, 5.6 is the key, and what identification there is to be found in 5.62 of language and my language is something indicated only in passing by means of parenthesis. Taking this appearance seriously provides, furthermore, a rather different perspective. On the one hand section 5.6 is, Wittgenstein says, the key: nothing substantially new is adduced in 5.62. On the other hand it is quite right that we arrive at solipsism only by means of a claim that the language is my language. So it must be that this claim is already present in section 5.6.

In fact, the presence in 5.6 of an identity between language and my language is the central point we made just above in response to the concern of impersonality, the concern that the subject of 5.6 is a subject. If there were an independent notion of truth in play in 5.6, so that it is as such a truth or falsity that I grasp something, then a very good question would indeed arise of why the limits of my language, the range of truth and falsity that I think, the possibilities for truth and falsity contained in the objects about which I think, should be the limits of the language, the possibilities for truth and falsity in general. I may make no sense of a deeper content to that which I possess in thinking, no sense of truth-independent substance. But how am I to rule out the possibility of wider content. How am I to rule out, that is, the possibility that what I think is a proper sub-space only of the space of truth and falsity? Here we do indeed need an extra premise that the language is my language, that language does not extend beyond mine, and it is very hard to see where this premise might come from. Once we recognise, however, that 5.6 does not draw on an external notion of truth, that its notion of truth is not something independent of graspability by me, then we may recognise a single key whose turning is as straightforward as Wittgenstein suggests.

It is as something I possess, as a determination of myself, that I possess something, and the thought of 5.6 is that I make no sense of what I think (my world) having substance independent of its possessability by me (my language). But as we have emphasized enough, the phrase 'possessability by me' does not instantiate a variable 'possessability by $x^{\prime}$. Rather, it is an essentially first personal idiom. Possessability by me precisely does not, then, implicate the idea of a potentially wider space of possessability simpliciter (possessability by a subject), a potentially wider space of truth, a potentially wider space of language. Rather, the truth in play in 5.6 is essentially linked to me, it means as much as: a determination of me. (The understanding is my understanding.) So it is already there, already present, in 5.6 that language is my language, that the limits of language mean the limits of that which I understand. And so the key is indeed effortlessly turned. I make no sense of that which I understand having truth-independent substance - an obtaining fact is a truth. And truth means as much as possessability by me. So the space of possible fact is nothing other than the space of that which I possess: the space of my determinations. The world is my world. 
We rejected above the possibility of an inference from 5.61 to 5.6. Attempting such a move would mean treating the subject as a subject, and so preventing any arrival in 5.62 at an engaging solipsism. It might now seem, however, that we have given an explanation in the opposite direction, from 5.6 to 5.61 . The subject makes no sense of content to her thinking going beyond in kind that which she possesses in thinking. This was our understanding of 5.6. And it is this, it might now seem, which explains truth's pride of place. 'Truth' means precisely that which the subject possesses. And with no sense being made of substance beyond such truth, the rejection of truth-independent substance expressed in 5.61 becomes a consequence of 5.6 .

Carefully understood, this view is I think correct. But care is indeed needed, for the position may seem alarmingly idealist. Truth and logic, it may seem, have become a mere reflection of me, the subject. The nature of truth is explained by reference to that of the subject. The core message of what Wittgenstein goes on to say in the $5.63 \mathrm{~s}$ and $5.64 \mathrm{~s}$ is that no such reflecting or explaining is in fact in play. There is no such idealism. Truth is not founded in the subject.

\section{2}

The substance of this message is delivered through Wittgenstein's treatment of the metaphor of the eye and its visual field. ${ }^{2}$ He writes:

5.633 Where in the world is a metaphysical subject to be noted? You say that this case is altogether like that of the eye and the field of sight. But you do not really see the eye. And from nothing in the field of sight can it be concluded that it is seen from an eye.

5.6331 For the field of sight has not a form like this:

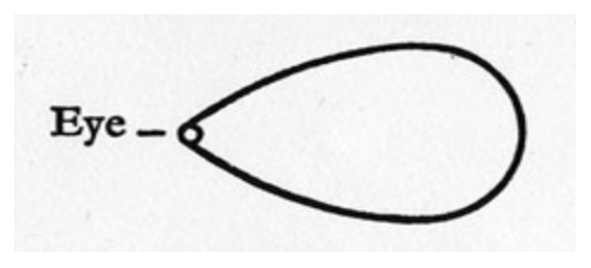

Wittgenstein doesn't reject the comparison outright between the eye and its visual field and the subject and its world, and he doesn't endorse it outright either. His principle concern is rather to repudiate a certain understanding of the metaphor, an understanding embodied in a tendency to draw the picture of 5.6331 .

There are two things wrong with the picture, Wittgenstein says. First, it places the eye within the visual field. This is an obvious mistake: the visual field is constituted by that which is seen by the eye, and the eye does not see itself. Or moving the mistake across to the subject and its world, the subject is not something within its world, an empirical object discernable there amongst others (c.f. 5.631). The subject is not something I speak or think about, an element of content for me. This is in effect our point above that the subject is not a subject. Rather, the subject is that whose range of determinations constitute its world. Or as Wittgenstein now puts it, 'I am my world' (5.63). In saying this, though, we threaten to run into the second mistake Wittgenstein identifies with the drawing of the visual field. 'From nothing in the field of sight,' Wittgenstein writes, 'can it be concluded that it is seen from an

\footnotetext{
${ }^{2}$ My discussion here is heavily influenced by Sullivan 1996.
} 
eye' (5.633). But insofar as the field and the eye are two sides of the same coin, surely everything in the field allows inference to the eye!

The inference from the field to the eye is indicated in the picture of 5.6331 by the field's having a boundary whose shape focuses in on a certain point, the position of the eye. And reflecting the apparent necessity of such an inference is the fact that there is surely nothing wrong with this shape. In drawing a visual field, we surely must draw a line whose shape draws in towards the position of the eye. But still, Wittgenstein says, this is not the form of the field of sight. How so? These problems are I think set here by Wittgenstein as parallel: how can I not be concluded from my world, and how can the eye not be concluded from its field? And a key message within this pair of sections, a key point of Wittgenstein's introduction of the metaphor, is that these parallel questions have parallel responses.

Whilst we can fuss about the exact position of the eye vis-à-vis the boundary when we draw the visual field, there is no getting away from the fact that insofar as we are drawing a visual field, we shall be drawing something which sets the location of the eye and in doing so speaks of the eye. And this is not something Wittgenstein wants to deny. His point is not that there is something wrong with the picture, that the picture needs to be changed so as to remove the suggestion of an inference from field to eye. His point is rather that the artist makes a mistake in drawing a picture at all. There is, Wittgenstein is saying, no picture to be drawn of the visual field. We can of course draw a visual field, an eye with a line showing the boundary of those things within its range. And insofar as this is a generic picture as opposed to a picture of a particular eye and its particular field, we can if we like call it a picture of the visual field. Crucially, though, and this is I think Wittgenstein's central point, any such drawing will necessarily involve a distancing by the artist of the eye. The visual field, that is to say, will necessarily not be drawn from the perspective of the drawn eye but from a different perspective, from a perspective outside the eye. Or again, in drawing the eye and its field, the artist necessarily looks down on them. Any attempt to avoid such looking down, to draw the field from perspective the eye, must fail: there is simply no drawing possible here, no lines the artist can make on the paper (c.f. Sullivan 1996 p198). (And conversely, where the artist is able to hold the eye at a distance, there will be no barrier to a drawing. Indeed, fuss about the exact location of the eye to one side, the artist will immediate produce the picture of 5.6331.)

An inference from its field to the eye is avoided, I'm suggesting, only by refusing to offer any drawing, where this is equivalent to refusing to treat the eye at a distance. And transferring across the metaphor, the thought will be that an inference from its world to the subject is avoided by recognising that such an inference both depends upon, and is the immediate consequence of, a distancing of the subject. Insofar as the inference is indeed a mistake, so too is the would-be distancing, and vice versa.

We have talked enough above about the undistanceability of the subject, about the subject's not being a subject. Wittgenstein now calls the subject, the self of self-knowledge, the 'metaphysical subject' $(5.633,5.641)$ or again the 'philosophical I' (5.641). And there is, he says, no inference to this I from what it possesses, its world or determinations. But the puzzle remains here of how there is no such inference. Merely invoking the visual field metaphor is not in itself an explanation. Yes, the self is not distanced. But the problem remains: where I am my world, how can I not be concluded from my world? How can there be no inference from its world to the subject?

\section{3}

Let's shift to think in terms of content, loosely conceived. A drawing of the visual field is made with lines. And these lines have meaning, they indicate something: they express content, and so difference. Here, this stuff, is in the field; there, this other, is not. Such a drawing is immediately available of the distanced eye and its field: distancing the eye and its 
field means, precisely, seeing something from a distance, and so having material for a drawing. And the converse is also true: having something to draw, finding content to the eye and its field, means distancing the eye. Lines can be drawn, content found, only from a perspective other than that of the eye. Following the metaphor, the thought will then be that the undistanced subject and her world will as such be empty of content. And with this thought we find an answer - though perhaps an enigmatic one - to the question how there is no inference from the world to its subject. There is no inference because there is no content to which an inference can be made, or indeed content from which an inference can be made. The subject is indeed the internal unity of its world, the unity of truth, but the undistanced unity is an empty unity, a unity empty of content, a unity without contrast.

The idea of a contentless subject is evident in the following section 5.634:

This is connected with the fact that no part of our experience is also a priori.

Everything we see could also be otherwise.

Everything we describe at all could also be otherwise.

There is no order of things a priori.

Where as I am my world, any content to me would be an a priori necessity for me, content given to me merely in thinking. In thinking, the subject's determinations are given to her as such. So any content to her determinations would be content to her world, that is content to the world, given to her merely in thinking. The subject would know merely in thinking that the world has this character, the character of herself. But there is, Wittgenstein is insisting, no character to the subject and her world. And so there is no such knowledge, no such a priori order. But still, whence this insistence? So far, the emptiness of the subject is the product only of the application by Wittgenstein of a certain metaphor, the transferal across a metaphor of the idea that there is no drawing the field from the perspective of the eye. But why should the metaphor apply?

Well, here we need to look back to 5.6 and 5.62. The application of the metaphor of the eye and its field is not the development of a substantially new picture for Wittgenstein; rather, the applicability of the metaphor is implicit already within the fact that the limits of my language mean the limits of my world.

Finding content to the subject and her world means making a contrast between the subject's world and 'not the subject's world', a contrast between the subject's world and what lies outside that world, the range of determinations known to the subject in being so determined. It means, that is to say, being in position to draw a contentful line, a picture of the subject's world. Or again, it means saying that the subject's world has this in it, and this, but not that. As rehearsed in part 1, however, saying that the world of possibilities has this in it, and this, but not that, depends upon finding possibility-independent substance to the world. And saying that the subject's world has this in it, and this, but not that, will depend upon finding substance to the subject's world independent of the subject, substance to the subject's determinations independent of their being the subject's determinations. Just as finding content to the space of possibility so that we can say that this is possible but not this depends upon finding substance independent of possibility, so too finding content to the space of the subject's determinations depends upon finding substance independent of those determinations, substance independent of the subject. Our elaboration above of 5.6 centrally involved, however, the idea that finding content independent of herself is precisely what the subject does not do. I make no sense of the supposition that what I think outruns in its content that which I possess in thinking: the limits of my language mean the limits of my world. The subject makes no sense of substance beyond herself. But this means at the same time, we're now underlining, that she makes no sense of substance to herself. Finding no 
substance beyond the subject means at the same time finding no substance to the subject. The undistanced subject of 5.6 is thus as such an empty subject.

\section{4}

Wittgenstein expresses this thought in 5.64 by saying that 'the I in solipsism shrinks to an extensionless point'. More fully he writes:

5.64 Here we see that solipsism strictly carried out coincides with pure realism. The I in solipsism shrinks to an extensionless point and there remains the reality co-ordinated with it.

And with this, the solipsism story of the Tractatus is effectively closed. So where are we?

At the start of this third part of the essay, we entertained the thought that in explicating truth by reference to the subject, the solipsist has cast truth as a reflection of the subject, that the solipsist has explained the nature of truth, the nature of sense, by reference to that of the subject. And this is indeed precisely what would have happened if there were content to the solipsist's I. 'Sense is what I make sense of', 'A possibility is a determination of this, of $m e^{\prime}$ - said with appropriate emphases. But this is not what has happened. Indeed, it cannot be what has happened, for such an explanation would immediately undermine itself. Where substance is ascribed to the subject, substance is imputed beyond the subject, with the result that there will be no pride of place for the subject, and so for truth. Section 5.61 will thus have been not explained but falsified.

Our reasoning in part 2 did not entail, however, an explanation from the nature of the subject to that of truth: it merely ruled out that truth be independent of the subject. It is as something I possess, as a determination of myself, that I think something. And I make no sense of content beyond here, of content independent of possessability by me. From here truth will indeed need to be explained as possessability by me. But this explanation will not be of a substantial nature through reference to a substantial explanans, an idealist explanation of the nature of truth by reference to that of the subject and her powers, for in making no sense of content independent of the subject, I at the same time make no sense of content to the subject. What we shall have, rather, is an explication of truth as identical, in its emptiness, to the subject. As Wittgenstein puts it, we shall have not an idealism but a coincidence of solipsism with pure realism. The suggestion in solipsism of an idealism, of an explanation from the subjective, from what is given to and so belongs to the subject, to the objective, to what is characterized by truth, is illusory. Rather, solipsism, thought through, coincides with realism. Truth's pride of place is not derivative from a deeper pride of place of the subject, but is underivative.

From part 1 we wanted an understanding of truth's pride of place. By the end of part 2 we arrived at a suggestion that this is explained as reflecting something more fundamental than truth, namely the subject. And in part 3 we have seen this mooted explanation collapse as incoherent. In recognising this collapse, however, we at the same time gain the proper understanding of what would be explained. Truth's pride of place is not mere dogma. Nor is it explained by reference to something else, the subject. Rather, it is to be understood in its coincidence with the emptiness of the subject. The necessity of truth's pride of place is to be understood in its identity with the fact that thought makes no sense of content outside itself.

\section{References}

Frege, Gottlob (1979) Posthumous Writings. Oxford: Blackwell. 
Sullivan, Peter (1996) "The 'Truth' in Solipsism, and Wittgenstein's Rejection of the A Priori", European Journal of Philosophy 4 (2), 195-219.

Wittgenstein, Ludwig (1998) Notebooks 1914-1916. Oxford: Blackwell.

Wittgenstein, Ludwig (1971) Prototractatus. Oxford: Routledge.

Wittgenstein, Ludwig (1922) Tractatus Logico Philosophicus. London: Kegan Paul. 